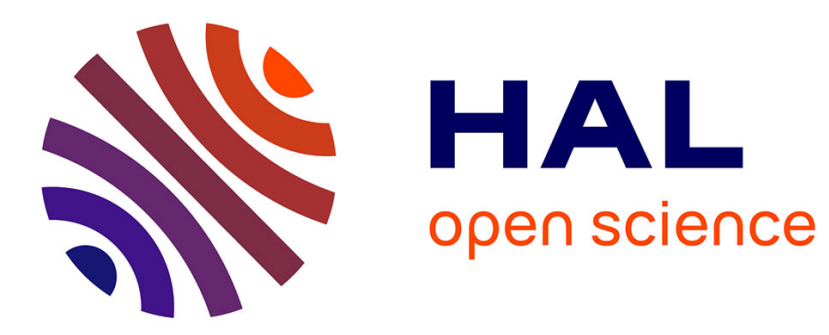

\title{
DENSE MATTER IN LASER DRIVEN FUSION : LABORATORY EXPERIMENTS
}

\author{
R. Mc Crory, J. Wilson
}

\section{To cite this version:}

R. Mc Crory, J. Wilson. DENSE MATTER IN LASER DRIVEN FUSION: LABORATORY EXPERIMENTS. Journal de Physique Colloques, 1980, 41 (C2), pp.C2-165-C2-177. 10.1051/jphyscol:1980227 . jpa-00219819

\section{HAL Id: jpa-00219819 https://hal.science/jpa-00219819}

Submitted on 1 Jan 1980

HAL is a multi-disciplinary open access archive for the deposit and dissemination of scientific research documents, whether they are published or not. The documents may come from teaching and research institutions in France or abroad, or from public or private research centers.
L'archive ouverte pluridisciplinaire HAL, est destinée au dépôt et à la diffusion de documents scientifiques de niveau recherche, publiés ou non, émanant des établissements d'enseignement et de recherche français ou étrangers, des laboratoires publics ou privés. 


\title{
DENSE MATTER IN LASER DRIVEN FUSION : LABORATORY EXPERIMENTS
}

\author{
R.L. MC Crory and J. Wilson \\ Laboratory for Laser Energetics - The University of Rochester - Rochester, NY 14623
}

\begin{abstract}
Résumé.- Nous présentons un exposé sommaire des performances et des caractéristiques des lasers à haute puissance $(1,054 \mu \mathrm{m})$ disponibles au "Laboratory for Laser Energeticș" à l'Université de Rochester. Les résultats récents d'expériences de fusion laser (puissance focalisée de $3 \mathrm{TW}$ ) qui ont abouti à une production de plus de 109 neutrons et des densités du coeur comprimé allant de $0,2 \mathrm{a} 4 \mathrm{~g} / \mathrm{cm}^{3}$ avec des températures ioniques de 1 à $8 \mathrm{keV}$ sont brièvement décrits. Une courte description des méthodes de diagnostique utilisées dans ces expériences est présentée. D'autres expériences de hautes densités d'énergie en progrès ou envisagées en dehors de la fusion laser sont évoquées. Des expériences d'intéraction laser-matière avec applications en astrophysique sont décrites dans l'intention de stimuler des propositions futures qui pourraient bien être désignées sous le nom "d'astrophysique de laboratoire".
\end{abstract}

Abstract. - We have presented a survey of laser plasma interaction expeximents currently in progress at the laboratory for Laser Energetics at the University of Rochester. Although our survey of this field is rather incomplete, it is hopped that this brief summary of capabilities will stimulate interaction investigations into high energy density interaction experiments made possible by the presently available high power lasers. In particular, it now appears possible to perform laboratory experiments which may properly be termed "laboratory astrophysics". It is anticipated that such experiments will amplify present astrophysical research related to dense matter by affording direct experimental measurement of important quantities, such as transoort coefficients, previously available only from theoretical calculations.

1. Introduction.- Background of Laser Plas-ma Interactions.-

State of the art high power laser ${ }^{1}$, which exist at only a few establishments, when focused on a target can generate energy densities as high as $10^{8}-10^{9}$ joules $/ \mathrm{cm}^{3}$, on time scales of $10^{-9}$ seconds or less, giving rise to field strengths in excess of $10^{10}$ $\mathrm{V} / \mathrm{cm}$. Energy densities of this magnitude open up several interesting areas of physics. For example, the intensities required to produce these energy densities can result in photon pressure greater than the particle pressure, and above $10^{5}$ joules $/ \mathrm{cm}^{3}$ high efficiency conversion into x-rays occurs.

Experiments to determine the equation of state and radiative opacity of matter under extreme conditions (densities in excess of 10 to $100 \mathrm{~g} / \mathrm{cm}^{3}$ and temperatures in excess of a few $\mathrm{keV}$ ) become possible. Because the physical conditions in these experiments overlap the regimes appropriate to the interiors of the giant planets and the surrace regions of white dwarf stars, the experiments are of interest to certain astro- physical applications. These conditions generate neutrons and intense $x$-rays from what is essentially a point source. The brief intense $x$-ray energy has application in areas such as biomedical research, particularly for time-resolved studies.

The high power lasers in quaestion were constructed with laser fusion studies as the goal, i.e., experiments designated to make progress towards controlled thermonuclear fusion 2,3 by using laser irradiation to heat and compress a target containing thermonuclear fuel to fusion conditions. This is still the major task of these lasers. Nevertheless, in view of the unusual conditions generated in this process there exist apolications of this system to various scientific disciplines.

The lasens, available at the Iaboratory For Laser Energetics are briefly described and combared with alternate facilities. theoretical calculations employing hydrodynamic simulation codes in one- and two dimensions are compared with laser Eusion experiments. Experimental results are presented in summary form for three current experiments which illustrate a variety of the 
techniques currentlyin use for such experiments.

2. Description of laser systems at the Laboratory for Laser Energetics.- The facilities existing at the Laboratory for Iaser Energetics for experiments in high energy density physics are the GDI and ZETA lasers, with their target areas, and a target fabrication laboratory. In early 1980, the six-beam ZETA laser will be converted to the higher powered, twenty-four beam OMEGA laser. ${ }^{4-7}$ Descriptions of these systems are given below. The laboratory has a CDC 6600 computer operating on site used for the theoretical calculations. The computer facility will be upgraded to a CDC cyber 175 computer on site in October, 1979.

The Glass Development Laser (GDL)

The Glass Development Laser (GDL), 4 in operation since october 1.977 is a prototype of the existing ZETA laser system and the complete high power OMEGA laser system presently being developed at the LLE. The GDL constitutes one beamline of the ZETA and OMEGA $^{7}$ systems from oscillator to the final $90 \mathrm{~mm}$ diameter rod amplifier. The design and performance of the GDL is given in figure 1.

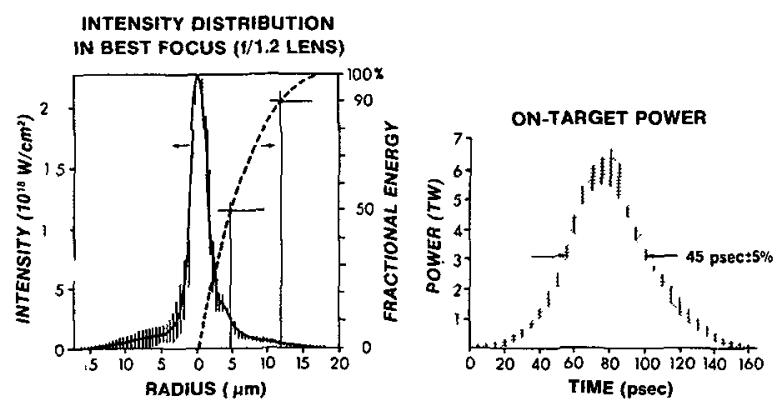

Figure 1 : Performance of the Glass Development laser

\section{The ZETA Laser Facility}

The ZETA Laser system is the present high power 6 beam laser system in operation at the LLE. This system has been designed so that it will naturally evolve into the higher power 24 beam OMEGA laser system. ZETA and its upgrade OMEGA, will be a unique tool available to users for a wide range of experiments.

Table 1 summarizes the performance of the ZETA Iaser system.

Table 1

ZETA facility performance objectives

Energy

Focusable power

Beam divergence

Pulse shape

Wavelength

Irradiation uniformity

Preheat suppression

Beam aperture

No. of beams

\section{Iaser Subsystem}

The oscillator 5 and rod driver portion of the system 8,9 generates a tunable width pulse of 1.054 micron wavelength, amplifies it, and gates it out to the beam splitter and main amplifier sections $10,11,12,13$ of the system. Two oscillators, with Pockels cells switch out, allow rapid change of the pulse characteristics. The oscillator is followed by four rod amplifiers, the largest of which is $64 \mathrm{~mm}$ in diameter. Spatial filters and pockels cells are included between each stage of amplification. Pulses can be shaped to satisfy a broad range of target/experimental parameters. The beamsplitting subsystem divides the single output beam from the rod driver line output into 24 equal beams in a two step process. The first step divides the single beam into 6 beams and provides one stage of amplification (via $64 \mathrm{~mm}$ diameter rod amplifiers) for each beam. These six beams are each split into 4 beams for a total of 24. Of this total of 24 , designed for the later OMEGA System, only 6 are used for ZETA. Beam lengths are adjusted in the beamsplitting section to provide equal optical paths to the target chamber. Rough path length adjustment is provided by nominal placement of folding mirrorsin each beam. Remotely controlled fine adjustments using a movable corner cube mirror may be made in response to a beam timing interferometer error signal. The 6 beam 
lines perform amplification using $64 \mathrm{~mm}$ and $90 \mathrm{~mm}$ aperture rod amplifiers to obtain $3 \mathrm{TW}$ peak power (50 psec FWHM). Figure 2 gives the output energy as a function of laser pulsewidth for the ZETA system, and also for the later OMEGA system, which has 24 beamlines.

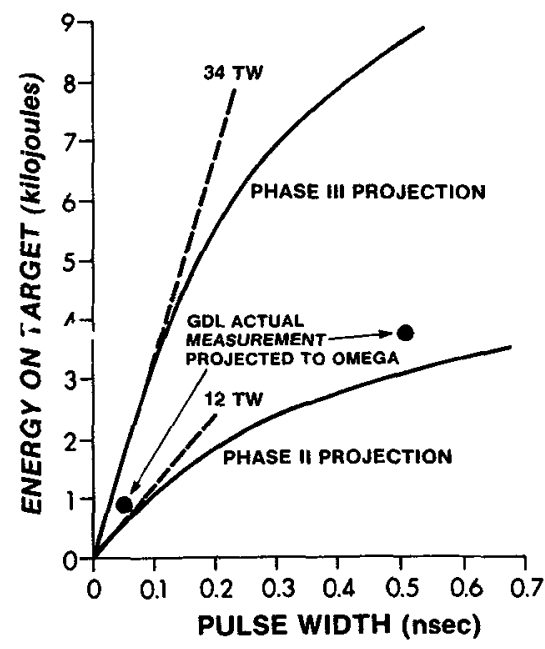

Figure 2 : Output Energy as a Function of Pulse Length for the ZETA and OMEGA Laser Systems.

The 6 beamlines are arranged in one group of four beams, and a group of two beams. Each group contains amplifier, spatial filter, Pockels cell, and beam splitting structures. Space is contained in each structure to house the appropriate electrical and hydraulic hardware.

Optical diagnostic studies of the output of the laser system are obtained by allowing 1 percent of the main laser beams to pass through the end injection mirrors. Diagnostic areas located behind these mirrors receive flux that has passed through the injection mirrors and analyze it to determine its energy and farfield irradiance.

\section{Target Chamber and Focusing Lenses}

The target area includes a target chamber, focusing lenses and their drives, target viewing system, target positioner, and vacuum system. The target chamber is a steel sphere approximately $70 \mathrm{~cm}$ in diameter. The chamber has 26 equally spaced ports, 6 of which, symmetrically arranged, are used for beam focusing lenses. The remaining diagnostic ports support a target positioner, vacuum system, alignment viewing system, and various diag- nostics. The vacuum system for the chamber provides a pressure of $10^{-6}$ Torr to prevent gas breakdown near the focal region. The target system has the flexibility of holding up to 15 targets, and positioning a single target at the common focal spot for the 6 beams. The target positioning system has a maximum error of approximately 2 microns in the placement of an individual target.

A large number of measurements is required to characterize the laser interaction experiment. Diagnostics are typically either mounted on flanges of the target chamber or are external to the chamber. Examples of diagnostics inside the chamber are calorimeters to measure both the scattered light and plasma energy ; and $x$-ray diagnostics to measure the spatial and temporal emission of the continuum and line components. Examples of diagnostics external to the chamber are incident and backscatter calorimeters to measure the incicident and backscattered energy, and neutron counters to measure the total neutron yield from fusion reactions in the target. Calorimeters ${ }^{14}$ are used for measuring the energy of ions and $\mathrm{x}$-ray.

In these experiments part of the incident laser energy is absorbed and then reemitted mostly as ions and $x$-rays, and part is scattered from the target without being absorbed.

In the total energy balance experiment, the incident laser energy is measured using beam calorimeters. These same types of calorimeters are used to measure the backreflected energy from the target through the focusing lenses. The remainder of the energy balance is measured using the calorimeters described above.

The plasma calorimeter is a differential device consisting of two sensor regions; one measures the plasma energy, the other only scattered laser energy. The difference between these two is then the plasma energy. Each calorimeter has a built-in hatch for calibration of the device.

\section{The OMEGA Laser system}

Since the OMEGA Laser System is an extension to 24 beams of the 6 bearn ZETA Laser 
System, it will surffice to describe the major differences between the two systems. There are two such differences; in the targest systems and in the alignment systems.

\section{Target System}

The focusins lens and target chamber designs will be altered from those used in ZETA. The basic concept developed for OIIEGA is a single element convex aspheric lens with a separate plane parallel vacuum window. Preliminary calculations indicate that an $\mathrm{f} / 3.2$ lens of approximately $600 \mathrm{~mm}$ focal length is free of internal ghosts and has a 3 milliradian field of view. The aspheric surface will depart from the closest sphere by only 60 micrometers and has aspheric constants of only fourth and sixth order. This lens is well within the state-of-theart of current optical fabrication techniques and $\lambda / 10$ performance over $90 \%$ of the aperture should be obtainable in production quantities.

\section{Alignment}

The four major functions, centering, pointing, focusing, and timing have been accomplished with a manual alignment system on ZETA. The increase in complexity from the ZETA to OME$G$ A system, both in scale and number of components, has necessitated the implementation of a computer controlled alignment system. Key features of this system are (1) remote control of critical components, (2) computer monitoring and reporting of system status, (3) computer monitoring of alignment hardware to determine and locate system malfunctions, and (4) computer maintenance of a data log of key parameters and system history.

\section{Target Fabrication Laboratory}

Present facilities allow for the selection, characterization and fabrication of a variety of targets for laser-fusion and laser matter interaction experiments. $15,16,17$ These targets span a wide range of sizes, geome tries and compositions. Physical and analytical methods for their preparation, inspection and mounting have been assembled. Seve- ral of these techniques 18 are at the forefront of targest fabrication technology.

3. Characteristics of the system and comparison with other facilities.- The laser system described above, of interest to experimenters studying laser fusion and laser-matter interaction, need not concern experimenters only interested in radiation from the target. The laser irradiated target is effectively a point source ( $\leqslant 100 \mu \mathrm{m}$ ) of $\mathrm{x}$-rays, neutrons and charged particles. The $x$-rays and charged particles can be refocused at a distance from the target. This property of the $x$-rays has been used in a recently completed biophysics experiment. 48

The fluxes of these quantities are given in Table 2 below.

Table 2.

Fluxes from laser-irradiated targets

\begin{tabular}{|c|c|c|}
\hline Item & ZETA & OMEGA \\
\hline$x$-rays & $\begin{array}{l}\text { Yield* }-10^{14} \text { photons into } \\
4 \pi \text { steradians } \\
\text { Rate }-10^{24} \text { photons } / \mathrm{sec} \\
\text { Wavelength } 2-5 \AA\end{array}$ & $\begin{array}{l}-10^{15} \text { photons into } \\
4 \pi \text { steradians } \\
\sim 10^{25} \text { photons } / \mathrm{sec} \\
2-5 \AA\end{array}$ \\
\hline Neutrons & $\begin{array}{l}\text { Yield } \approx \begin{array}{l}10^{9} \text { neutrons into } \\
4 \pi \text { steradians }\end{array} \\
\text { Rate } \approx 10^{19} \text { neutrons } / \mathrm{sec} \\
\text { Energy } 14 \mathrm{Mev}\end{array}$ & $\begin{array}{l}\text { Yield } \approx 10^{11} \text { meutrons } \\
10-15 \mathrm{TW} 1 \text { aser power } \\
\text { Rate } \approx 10^{21}-10^{23} \text { neutrons/s } \\
\text { Energy } 14 \mathrm{MeV}\end{array}$ \\
\hline $\begin{array}{l}\text { Charged } \\
\text { Particles }\end{array}$ & \multicolumn{2}{|c|}{$\begin{array}{l}\text { Yield of } \alpha^{\prime} s=\text { Yield of Neutrons } \\
\text { Energy of } \alpha^{\prime} s=3.5 \mathrm{Mev} \\
\text { Yield of protons }=10^{-2} \times \text { (yield of neutrons) } \\
\text { Energy of protons }=3.03 \mathrm{Mev}\end{array}$} \\
\hline
\end{tabular}

*In a narrow spectral channel, $\frac{\Delta \lambda}{\lambda}=5 \times 10^{-3}$

To determine whether the laser irradiation system has unique properties, its characteristics must be compared with alternate facilities. Thus if one considers the laser produced plasma as an $x$-ray source, it is pertinent to ask how it compares with other $x$-ray sources. A major source of $x$-radiation at the present time is synchrotron radiation. Synchrotron radiation is orders of magnitude more intense than existing $c . w$. sources of $x$-rays. However as shown in Table 3 , the $x$-rays from laser plasmas are orders of magnitude more intense than the $x$-ray radiation fxom synchrotrons. This new intense source of $x$-rays will open up new areas of exploration. It mas be pointed out that whereas synchrotron radiation is broadband, the laser plasma x-ray emission can 
be made nearly monochromatic (Fig.3).

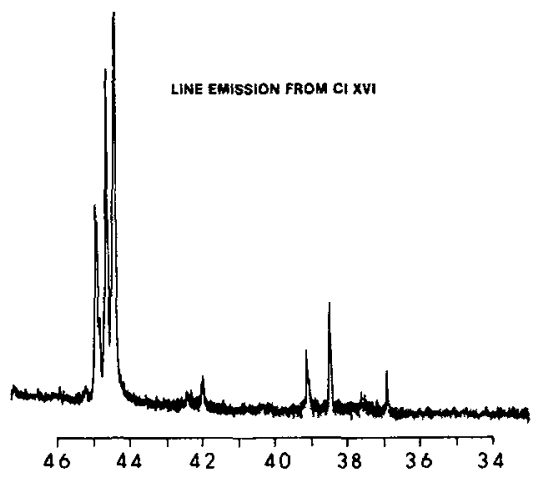

Alternatively, the plasma may be viewed as a source of neutrons. At present, the neutron production from laser compressed targets is less than from other devices. Various neutron producing devices are iisted in Table 4. Laser plasma sources are seen to be unique in two respects ; first the neutrons come effectively from a point source, and secondly the rate of production of neutrons is extremely high. Ultimately, as higher powered lasers available, the neutron production will increase to values comparable with other devices.

Fig.3.- Spectrum of $\mathrm{X}$-ray Emission from Laser-irradiation Saran Targets, showing the Quasi-ifonochromatic Enission at $4.45 \AA$.

Tabie III

$X$-RAY PRODUCTION

\begin{tabular}{|c|c|c|c|c|c|c|c|c|}
\hline Technique & $\begin{array}{c}\text { Photon } \\
\text { Rate } \\
\text { (No/sec) }\end{array}$ & $\begin{array}{l}\text { Pulse Length } \\
\text { (Secs) }\end{array}$ & $\begin{array}{c}\text { Energy/Pulse } \\
\text { (Joules) }\end{array}$ & $\begin{array}{l}\text { Number of } \\
\text { Exposures } \\
\text { Required }\end{array}$ & $\begin{array}{c}\text { Time } \\
\text { Resolution }\end{array}$ & $\begin{array}{l}\text { Energy } \\
\text { Range } \\
\text { (Kev) } \\
\end{array}$ & n Collector & $\begin{array}{l}\text { Bandwidth } \\
(\Delta \lambda / \lambda)\end{array}$ \\
\hline $\begin{array}{l}\text { Laser Plasma } \\
\text { (ZETA) }\end{array}$ & $10_{4 \pi}^{24}$ into & $10^{-9}$ & 20 into & 1 & $10^{-9}$ & $2.7-7.1$ & $10^{-5}$ & $10^{-2}$ \\
\hline \multicolumn{9}{|l|}{ Synchrotron } \\
\hline i) Brookhaven & $\begin{array}{l}20^{15} \text { into } \\
5 \times 10^{-6} \mathrm{sr} .\end{array}$ & $10^{-9}$ & $\begin{array}{c}5 \times 10^{-8} \text { into } \\
5 \times 10^{-6} \mathrm{Sn}\end{array}$ & $-10^{2}$ & $?$ & $0.1-50$ & & $10^{-2}$ \\
\hline if) Stanford & $\begin{array}{l}10^{15} \text { into } \\
5 \times 10^{-6} \mathrm{Sr} .\end{array}$ & $10^{-10}$ & $\begin{array}{l}5 \times 10^{-9} \text { into } \\
5 \times 10^{-6} \mathrm{Sr} .\end{array}$ & $-10^{3}$ & $?$ & $0.1-25$ & & $10^{-2}$ \\
\hline
\end{tabular}


Table IV.

\begin{tabular}{|c|c|c|c|c|c|c|c|}
\hline Facl! ity & $\begin{array}{l}\text { Neutrons/ } \\
\text { Puise }\end{array}$ & $d N / d t$ & Peak Flux & Fluence & $\begin{array}{l}\text { Neutron } \\
\text { Energy }\end{array}$ & $\begin{array}{l}\text { Repetition } \\
\text { Rate }\end{array}$ & Comments \\
\hline 1 aser Fusio & & $\begin{array}{l}\text { Neutrons/ } \\
\text { Sec }\end{array}$ & $\begin{array}{l}\text { Neutrons/ } \\
\mathrm{cm}^{2}: \text { Sec }\end{array}$ & Neutrons/ & e.v. & & \\
\hline $\begin{array}{l}\text { ULE - ZETA } \\
\text { - OAEGA (In }\end{array}$ & $10^{10^{1}}-10^{12}$ & $\begin{array}{l}10^{19} \\
10^{21}\end{array}$ & $\begin{array}{l}10^{18} / R^{2} \\
10^{20} / R^{2}\end{array}$ & $\begin{array}{l}10^{8} / \mathrm{R}^{2} \\
10^{10 / \mathrm{R}^{2}}\end{array}$ & $\begin{array}{l}14.1 \times 10^{6} \\
14.1 \times 10^{6}\end{array}$ & $\begin{array}{l}30 \mathrm{~min} \\
30 \mathrm{~min}\end{array}$ & $\begin{array}{l}\text { 1) Point Source (30um) } \\
\text { ii) Nat. User Facility }\end{array}$ \\
\hline $\begin{array}{l}\text { construction) } \\
\text { - OMEGA } \\
\text { Upgrade (Proposed) }\end{array}$ & $10^{12}-10^{13}$ & $10^{22}$ & $10^{21} / R^{2}$ & $10^{11 / R^{2}}$ & $14.1 \times 10^{6}$ & $30 \mathrm{~m} / \mathrm{n}$ & \\
\hline $\begin{array}{l}\text { LLI - SHIVA } \\
\text { Magnetic Fuston }\end{array}$ & $3 \times 10^{10}$ & $3 \times 10^{20}$ & $3 \times 10^{19} / R^{2}$ & $3.10^{9} / R^{2}$ & $14.1 \times 10^{6}$ & $4 \mathrm{hrs}$ & Point Source \\
\hline $\begin{aligned} \overline{\mathrm{LLL}} & -2 \times 1 I B \\
& - \text { MFTF }(\mathrm{tn}\end{aligned}$ & $\begin{array}{l}10^{11} \\
10^{16}\end{array}$ & $\begin{array}{c}10^{13} \\
2 \times 10^{16}\end{array}$ & $\begin{array}{c}16 \times 10^{11} \\
10^{12}\end{array}$ & $\begin{array}{l}1.6 \times 10^{9} \\
5 \times 10^{11}\end{array}$ & $\begin{array}{l}2.5 \times 10^{6} \\
2.5 \times 10^{6}\end{array}$ & $5 \mathrm{~min}$ & $\begin{array}{l}\text { Spherical Source }(7 \mathrm{~cm}) \\
\text { Spherical Source }(40 \mathrm{~cm})\end{array}$ \\
\hline $\begin{array}{l}\text { construction) } \\
\text { Princeton }-\mathrm{PLT}\end{array}$ & $2 \times 10^{13}$ & $2 \times 10^{14}$ & $8 \times 10^{8}$ & $8 \times 10^{7}$ & $2.5 \times 10^{6}$ & $3 \mathrm{~m} ; n$ & Torofdal Source $r=.5 \mathrm{~m}$ \\
\hline -TFTR (in constr.) & $2 \times 10^{18}$ & $-4 \times 10^{18}$ & $3 \times 10^{12}$ & $1.5 \times 10^{12}$ & $14.1 \times 10^{6}$ & $5 \min$ & $\begin{array}{r}\text { (R-1.3m) } \\
\text { Toroidai Source }\end{array}$ \\
\hline $\begin{array}{l}\text { TFTR-TFM (proposed) } \\
\text { Spallation }\end{array}$ & f) $2 \times 10^{19}$ & $-10^{19}$ & $9 \times 10^{12}$ & $2 \times 10^{13}$ & $14.1 \times 10^{6}$ & 5 min & $=1.1 \mathrm{~m}$ \\
\hline Argonne - IPNS-I & $7.5 \times 10^{13}$ & $10^{19}$ & $\begin{array}{c}4 \times 10^{16} \\
10^{15}\end{array}$ & $\begin{array}{r}10^{11} \\
3 \times 10^{10}\end{array}$ & $\begin{array}{c}>10^{5} \\
\text { Thermal }\end{array}$ & $\begin{array}{l}2 \times 10^{-2} \\
2 \times 10^{-2}\end{array}$ & $\begin{array}{l}\text { Cylindrical Source } \\
\phi=10 \mathrm{~cm}, 15 \mathrm{~cm} \text { long } \\
\text { Moderator Source }\end{array}$ \\
\hline Argonne - IPNS-II & $1.5 \times 10^{15}$ & $-10^{20}$ & $\begin{array}{c}8.5 \times 10^{17} \\
10^{16}\end{array}$ & $\begin{array}{l}3 \times 10^{12} \\
3.10^{11}\end{array}$ & $\begin{array}{c}>10^{5} \\
\text { Therma } 1\end{array}$ & $\begin{array}{l}1.6 \times 10^{-2} \\
1.6 \times 10^{-2}\end{array}$ & \\
\hline $\begin{array}{l}\text { LASL - WNR }(1.0) \\
\text { Reactor }\end{array}$ & & & $3 \times 10^{14}$ & $3 \times 10^{9}$ & Thermat & $8.10^{-3}$ & \\
\hline FTR & & & $4 \times 10^{15}$ & $4 \times 10^{15} t$ & $>10^{5}$ & Continuous & \\
\hline $\begin{array}{l}\text { Accelerator } \\
\text { LLL RTNS II } \\
\text { Plasma Focus }\end{array}$ & & & $1.5 \times 10^{13}$ & & $14.1 \times 10^{6}$ & Continuous & \\
\hline $\begin{array}{l}\text { Livermore Plasma } \\
\text { Focus } \\
\text { (a)so LASL, Euratom) }\end{array}$ & $3.5 \times 10^{11}$ & $7 \times 10^{18}$ & & & $2.5 \times 10^{6}$ & $-\cdots$ & $\begin{array}{l}\text { Not thernonuclear neutrons } \\
\text { Source }-R=1 \mathrm{~cm}\end{array}$ \\
\hline
\end{tabular}

4. Laser fusion experiments.- Experiments to date at the Laboratory for Laser Energetics have been carried out on the GDL and ZETA lasers, and an older laser called DELTA, capable of $0.2 \mathrm{TW}$ output, $19,20,21$ in four beams. Most of the experiments have been directed towards laser fusion, either directly, or indirectly by investigating some aspect of the laser-matter interaction relative to inertial confinement fusion. The experiments consist of focusing the laser energy onto a target, such that the target is raised to high energy density conditions. Typical targets have been cylinders of frozen deuterium or polyethylene, flat plates of various materials, solid spheres and hollow glass microspheres, with $100 \mu \mathrm{m}$ diameter, and I $\mu \mathrm{m}$ wall thickness, filled with DT fuel at several atmospheres pressure. Whatever target is used, the quantities of interest in the experiments are the densities and temperatures achieved, the durations of these conditions, particle energies, and the dimensions, particularly of the compressed core. The range of measurement parameters are
Ion Densities

Temperature

Particle Energy

Spatial Resolution

Temporal Resolution

$$
\begin{aligned}
& 10^{18} \mathrm{~cm}^{-3} \text { to } \\
& 10^{26} \mathrm{~cm}^{-3} \\
& 10 \mathrm{ev} \quad \text { to } \\
& 50 \mathrm{keV}
\end{aligned}
$$

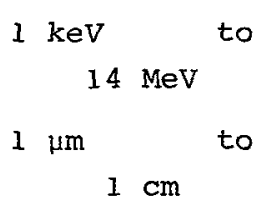

1 psec. to 100 nsec.

One fundamental measurement in laser-fusion research is the neutron yield, since this gives the degree of thermonuclear reaction achieved, and the energy liberated. In general, the neutron yield increases as the laser power on target increases. It is the scaling of the neutron yield with laser power that will determine the feasibility of laser fusion as an energy source, and which is therefore the subject of intense investigation. Figure 4 shows the yield as a function of laser power as determined in experiments at three laboratories, namely the Laboratory for laser Energetics (ILE), 30,31 Los Alamos Scientific Laboratory 


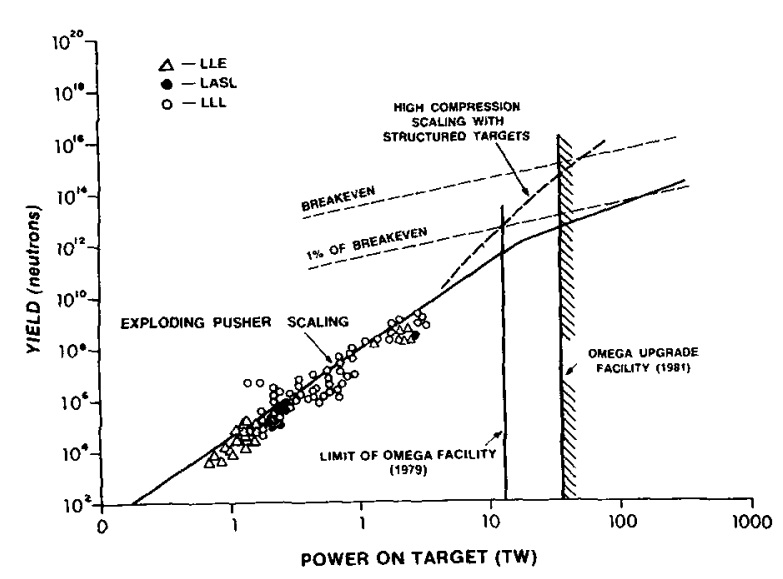

Figure 4 : Scaling of Neutron yield with Incident Laser Rower (100 psec pulse, FWHM).

(LASL) ${ }^{32,33}$ and Lawrence Livermore Laboratory

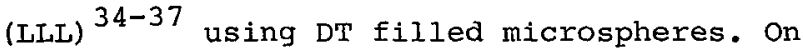
being irradiated, the glass shells of these targets explode outwardly and inwardly in a fashion known as "explodin pusher". The explosive-pusher mode means that the glass shell is exploded by suprathermal electrons (of long mean free path) which deposit their energy throughout the target outer shell. Thespurce of fast electrons is taken to be. Maxwellian at the critical surface, (At the critical surface the electron plasma frequency equals the laser frequency, i.e., $\mathrm{n}_{\text {ec }}=10^{21}\left(\frac{1.06}{\lambda}\right)^{2}$ electrons $/ \mathrm{cm}^{3}$ where $\lambda$ is the laser wavelength in microns) with a temperature $\mathrm{T}_{\mathrm{H}}$ obtained from experimental data and a fit from particle simulations performed by Estabrook and Kruer 38

$$
\mathrm{T}_{\mathrm{H}}=\mathrm{T}_{\mathrm{C}}+4.3 \times 10^{-6} \mathrm{~T}_{\mathrm{C}} \cdot 04\left(I \lambda^{2}\right) \cdot 42
$$

where $\mathrm{T}_{\mathrm{H}}$ ' $\mathrm{T}_{\mathrm{C}}$ are in $\mathrm{keV}$

$T_{C}$ is the thermal electron temperature $C$ at the critical surface,

$I$ is the incident laser intensity in $W / \mathrm{cm}^{2}$, and the laser wavelength $\lambda$. is in units of $1.06 \mu$.

When the fast electron dynamics are incorporated in the hydrodynamic caluulations, the theoretical scaling for exploding pusher behavior is obtained as shown in Figure 4 and gives good agreement with the experiments from all three laboratories. Structured targets, which are more massive, and hence need more laser power to achieve high energy density condi- tions, can show improved scaling over exploding pushers at very high powers. For example, Figure 5 shows the temperature and density during the compression and subsequent expansion of a structured target as calculated using the LLE design code LILAC. The principal ingredients employed in the computer codes and models in use at ILE are summarized in Table 5. For a more detailed description of these models, the reader is referred to references 22-29. The target illustrated in figure 5 was designed for high density, 30 and achieved a maximum calculated density of $200 \mathrm{gm} / \mathrm{cm}^{3}$, whereas exploding pusher targets in general do not exceed densities of $0.5 \mathrm{gm} / \mathrm{cm}^{3}$.

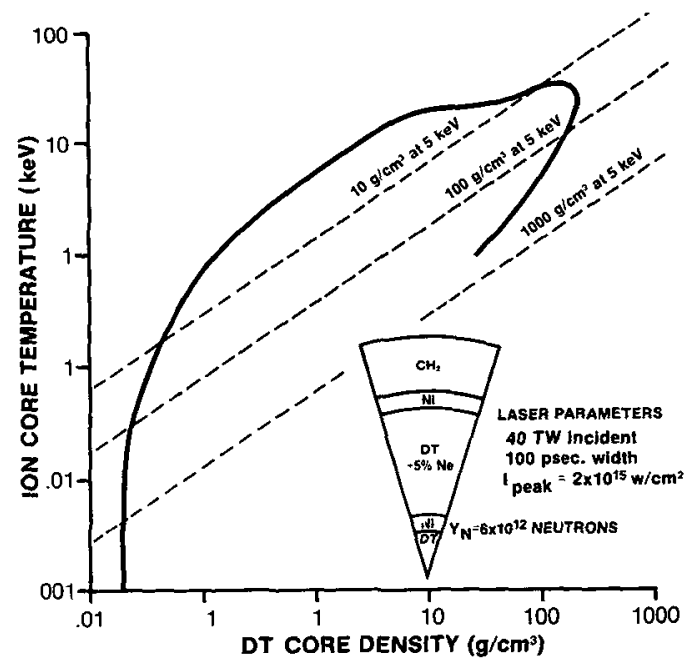

Figure 5 : Calculated Density-Temperature Trajectory for the structured Target Indicated. The Target Core is initially at the lower left corner, and moves up and to the right as it is compressed, reaching a máximum density of $200 \mathrm{gm} / \mathrm{cm}^{3}$. The dashed lines are isentropes.

To date experiments at $L L E^{31}$ have produced a neutron yield of $1.6 \times 10^{9}$ withl.65 Tw laser power ; at LLL, 34-37 $3 \times 10^{10}$ neutrons have been achieved with 20 TW of laser power. As increased laser power becomes available with the OMEGA laser, and using structured targets, up to $10^{13}$ neutrons/shot should be possible. Achieving high density is presently considered to be one of the most pertinent goals of laser compression experiments. Presently, there are three major experiments in progress at LLE designed to realize this goal. Table 6 summarizes the parameters of interests in the ZETA-X, 
$-T$, and $-p$ experiments.

In understanding the performance of laser fusion targets, measurements of the density $\rho$, and size $R$ of the compressed core of the target are important.
The measurement is performed by observing the $x$-ray spectrum from neon-filled pellets. Typical previous experiments for exploding pusher targets achieved densities near that of liquid DT, $2 \mathrm{~g} / \mathrm{cm}^{3} \cdot 39,40$

\section{BASIC CODES IN USE AT THE LABORATORY FOR LASER ENERGETICS}

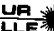

\begin{tabular}{|c|c|c|}
\hline \multirow[b]{3}{*}{$\begin{array}{l}\text { 岁 } \\
\stackrel{0}{0} \\
\frac{0}{0} \\
\frac{0}{2}\end{array}$} & LILAC & PANSY \\
\hline & One-dimensional target design & Hydrodynamic stability studies \\
\hline & Experimental data replication & \\
\hline \multirow[b]{7}{*}{ 悹 } & $\begin{array}{l}\text { Lagrangian hydrodynamics } \\
\text { Suprathermal electron Iranspont }\end{array}$ & $\begin{array}{l}\text { Surface harmonic perturbation } \\
\text { analysis }\end{array}$ \\
\hline & Laser absorption physics & $\begin{array}{l}\text { Lagrangian post-processor for } \\
\text { Lilac }\end{array}$ \\
\hline & Tabular equation of state & \\
\hline & Multigroup radiation transport & \\
\hline & TN burn, non-local deposition & \\
\hline & Atomic rate equations & \\
\hline & $\begin{array}{l}\text { Extensive post-processing and } \\
\text { output graphics capability (pin- } \\
\text { hole picture replication, reaction } \\
\text { product spectra, etc.) }\end{array}$ & \\
\hline
\end{tabular}

$\quad$ DAISY
Two-dimensional Lagrangian
hydrodynamics to analyze
illumination symmetry require-
ments; non-linear evolution of
hydrodynamic instabilities.
Flat target experiment
simulation

Triangular zoning

Lagrangian hydrodynamics

Laser ray-trace

Tabular equation of state

Electron/ion thermal conduction

R-Z geometry
SAGE

Code developed to examine selected two-dimensional

effects in actual experimen-

tation.

Magnetic fieid effects

Flat target experiment simulation

FCT Eulerian hydrodynamics with dynamic rezoning Tabular equation of state

Multigroup-diffusion treatment for suprathermal electron transport

Magnetic field dependen transport coefficients

X-Y, R-Z, R- $\theta$ geometry
Figure 6 shows a measured Argon Lyman- $\beta$ line taken from the ZETA- $\rho$ experiment. ${ }^{62,63}$ For the example shown, the experimentally achieved electron density is $7.7 \times 10^{23}$ electrons /CC, corresponding to a mass density of 3.0 $\mathrm{gm} / \mathrm{cc}$, roughly fifteen times the liquid density of DT.

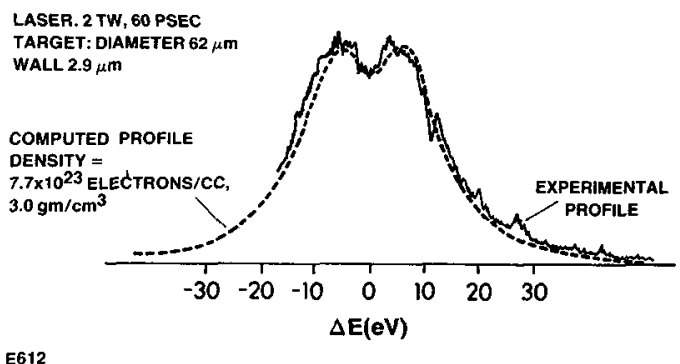

Figure 6 : Argon Lyman- $\beta$ Stark Broadened Profile Measured from the ZETA- $\rho$ experimental series.
The higher density was obtained by using thicker-shelled glass microballoon targets, and by taking advantage of higner $z$ fills (Argon) which permits, through radiation and ionization losses, cooling of the core alloring a higher compression. 30 The achievable density is a strong function of symmetry of the compression. In these experiments, a high degree of symmetry is achieved by adjusting the focal positions of the six beams. ${ }^{31}$ The use of short $(50$ psec) intense ( 2 to $3 \mathrm{TW}$ ) laser pulse results in relatively high absorption (30\%) and an apparently stable, symmetric, implosion as evidenced by the time integrated pinhole photographs (see below). The direct density measurements of the compressed core by fitting the calculated stark profiles 40 is presently the most reliable 
and sentitive of various methods to determine the density. ${ }^{41,42}$ In this series of experiments; good agreement was obtained (for densities in the $3-4 \mathrm{~g} / \mathrm{cm}^{3}$ range, using temperature values obtained independently from the spectrum) with the calculated time and space integrated profiles calculated by the IILAC code, ${ }^{62}$ which incorporates line radiation transport using the intrinsic profiles calculated by Hooper. ${ }^{43}$ Idealiy compression of the target would take place adiabatically. In determining how closely actual experiments approach the ideal, measurements of the density can be derived from the time resolved x-ray emission from the target. The measurement is made with an $x$-ray streak camera developed at the Laboratory for Laser Energetics. An example of an $x$-ray photograph 44,45 of an implosion is given in figure 7 taken from a shot from the ZETA-T experimental series.

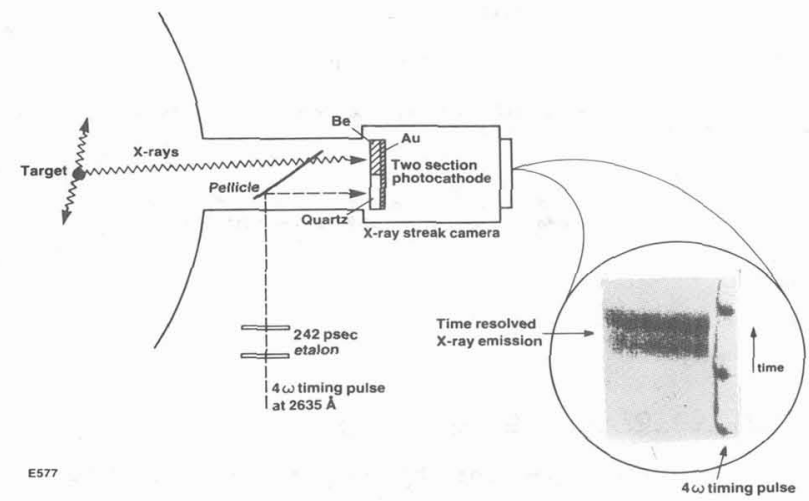

Fig.7.- X-ray Streak Camera and $4 \omega$ Timing Pulse (taken from the ZETA-T expeximental series).

Figure 8 illustrates the microdensitometer traces obtained from the $x-r a y$ streak camera from two other ZETA-T 60,61 shots. Time integrated $x$-ray pinhole photgraphs give a measure of the symmetry and compression achieved in an experiment. Two such $x-r a y$ pinhole photographs are illustrated in Figure 9.64

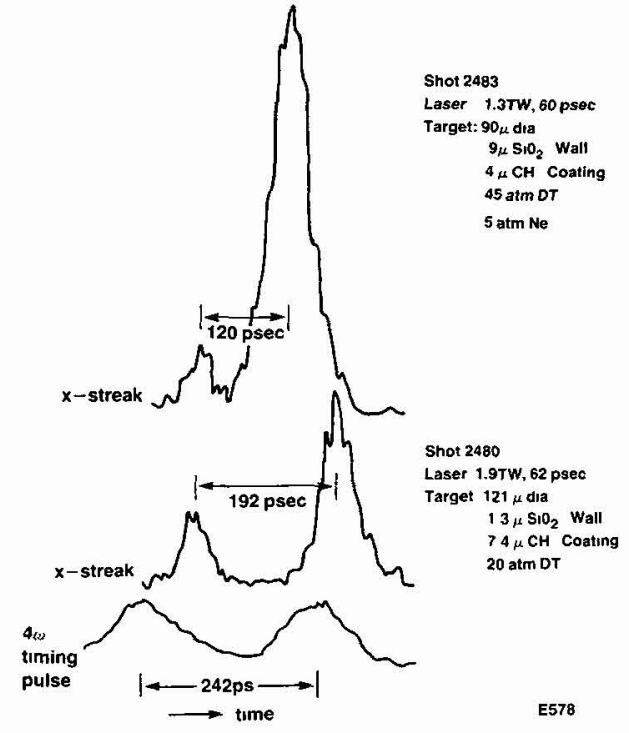

Figure.8.- Microdensitometer Traces of the Time Resolved $X-r a y$ Emission from Plastic coated microballoons from the ZETA-T experimental series.

It is hoped that this brief overview of recent laser fusion experiments gives the reader some insight into present capabilities of laser-matter interactions at high energy densities. In the following section a selection of present or proposed nonlaser fusion experiments is briefly surveyed.

The diagnostic equipment used in laser fusion experiments 46,47 is listed in Table 7 with a brief explanation of its use. This equipment is also available for non-laser fusion experiments.
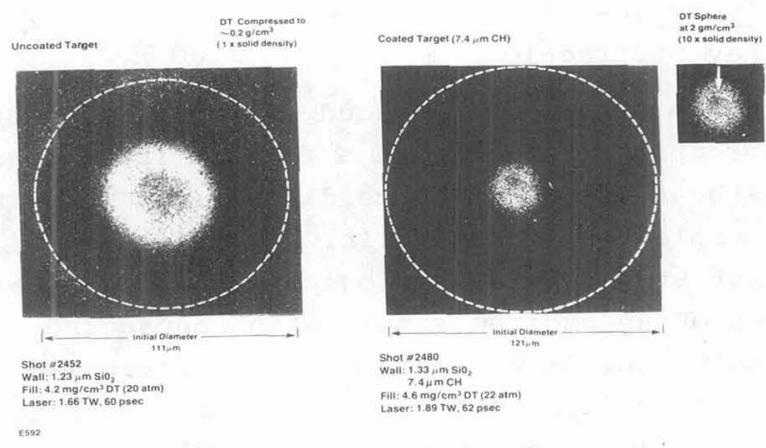

Fig.9.- Comparison of the Time Integrated $\mathrm{x}$-ray Pinhole Photographs of coated and Uncoated Targets from the ZETA-T experimental series. 
Table VI

ZETA EXPERIMENTS

\begin{tabular}{|c|c|c|c|c|c|c|c|}
\hline Experiment & Target & $\begin{array}{c}\text { Fue } 7 \\
\text { Density }\end{array}$ & $\begin{array}{c}\text { Fue } 1 \\
\text { Temperature }\end{array}$ & $\begin{array}{l}\text { Pulse } \\
\text { Width }\end{array}$ & $\begin{array}{c}\text { Neutron } \\
\text { Yield }\end{array}$ & Status & objectives \\
\hline$x$ & $\begin{array}{l}\text { Exploding } \\
\text { Pusher }\end{array}$ & $.2 \mathrm{gm} / \mathrm{cm}^{3}$ & $>5.0 \mathrm{Kev}$ & $<100 \mathrm{ps}$ & $>10^{9}$ & Complete & $\begin{array}{l}\text { Effects of symmetry and impio- } \\
\text { sion. Explosive pusher scaling } \\
\text { calibration of diagnostic } \\
\text { systems. }\end{array}$ \\
\hline T & $\begin{array}{l}\text { Plastic } \\
\text { Coated } \\
\text { CT-NEON, } \\
\text { ARGON }\end{array}$ & $\sim 2 \mathrm{gm} / \mathrm{cm}^{3}$ & $\sim 1.0 \mathrm{Kev}$ & $\sim 150 \mathrm{ps}$ & $\sim 10^{7}$ & In Pragress & $\begin{array}{l}\text { Obtain information on electron } \\
\text { energy transport by measurement } \\
\text { of collapse time. Measure com- } \\
\text { pressed density of } 1-2 \mathrm{~g} / \mathrm{cm}^{3} \\
\text { with neon line broadening. }\end{array}$ \\
\hline$\rho$ & $\begin{array}{l}\text { Radiation } \\
\text { Cooled }\end{array}$ & $\sim 10 \mathrm{gm} / \mathrm{cm}^{3}$ & $\sim 1.0 \mathrm{Kev}$ & $\sim 100 \mathrm{ps}$ & $\sim 10^{8}$ & In Progress & $\begin{array}{l}\text { Demonstrate the principle of } \\
\text { radiational cooling to achieve } \\
\text { measured compressed densities } \\
\text { 10 g/cm }{ }^{3} \text {. Develop high } \\
\text { density spectroscopic techni- } \\
\text { ques such as x-ray backlighting } \\
\text { and Argon if ine broadening } \\
\text { diagnostics. }\end{array}$ \\
\hline
\end{tabular}

Table VII: Zeta Dlagnostic Instrumentation

\begin{tabular}{|c|c|c|}
\hline Diagnostic & Instrument & Measures \\
\hline X-ray spatial distribution & $\begin{array}{l}2 \text { pinhole camera ( } 4 \text { channels) } \\
1 \text { x-ray microscope (4 channels) }\end{array}$ & $\begin{array}{l}\text { Symetry and approximate size of } x \text {-ray } \\
\text { emitting regions of target }\end{array}$ \\
\hline$x$-ray temporal characteristics & $1 \times$-ray streak camera & $\begin{array}{l}\text { Temporat and spatial behavior of } x \text {-ray } \\
\text { emission from target }\end{array}$ \\
\hline$x$-ray spectrum & $\begin{array}{l}1 \text { crystal spectrometer } \\
9 \text { channel K-edge filters } \\
3 \text { channel K-edge filters }\end{array}$ & $\begin{array}{l}\text { Target plasma density and size from spectral } \\
\text { broadening } \\
\text { Electron temperature of target }\end{array}$ \\
\hline Neutron count & $\begin{array}{l}1 \text { Cu activation counter } \\
1 \text { Ag activation counter } \\
1 \text { Fiuor }-p . m \text {. detector }\end{array}$ & $\begin{array}{l}\text { Number of neutrons produced by target } \\
\text { Number and energy of neutrons }\end{array}$ \\
\hline Alpha spectrum & 1 quadrupole spectrometer & $\begin{array}{l}\text { Ion temperature of target from spread of } \\
\text { a particle energy }\end{array}$ \\
\hline Ion energy and spatial distribution & 10 differential calorimeters & Energy absorbed by target \\
\hline Optical energy balance & $\begin{array}{l}6 \text { incident calorimeters } \\
6 \text { forward and backscatter calorimeters } \\
10 \quad 1.06 \mu m \text { calorimeters }\end{array}$ & $\begin{array}{l}\text { Distribution of optical energy, and energy } \\
\text { of laser puise }\end{array}$ \\
\hline Laser system perfomance & $\begin{array}{l}1 \text { near field streak camera } \\
1 \text { far field streak camera } \\
1 \text { prepulse monitor } \\
6 \text { near field beam photos } \\
6 \text { far field beam photos } \\
1 \text { pulse train monitor } \\
1 \text { switched out pulse monttor }\end{array}$ & $\begin{array}{l}\text { Pulse length, focal spot size, and energy } \\
\text { appearing ahead of main pulse, of laser } \\
\text { input }\end{array}$ \\
\hline
\end{tabular}

5. Non-laser fusion experiments underway or proposed. -

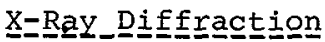

A pulse of $x$-rays produced by irradiating an appropriate target with a focused laser beam has been used to produce diffraction pattern of cholesterol and myelin. ${ }^{48}$ This is the first step towards biological dynamics studies on an excited sample with nanosecond resolution. Experiments would be performed by taking diffraction patterns of a sample at varying times following an applied stimulus. This technique could also be applied to chemical or physical changes in appropriate samples.

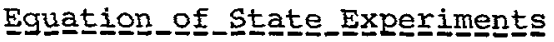

The high energy-density regime accessible by laser-target interaction consists of extreme conditions unattainable by any other laboratory techniques and overlaps conditions found in the giant planets and very cool white dwarf stars. Conventional laboratory techniques, using high pressure shock tubes at Lawrence Livermore Laboratory have reached pressures of several megabars. Very recently, static techniques have succeeded in producing metallic hydrogen at a pressure of 10 megabars. However, pressures of hundreds of megabars are generated in the shell of glass microballoons in laser fusion experiments, and pressures 
in the compressed core can be as high as 10 gigabars. For materials at these conditions both the equation of state and the radiative opacity, are unknown, ${ }^{49-51}$ and are not readily amenable to calculation. High power laser studies could thus provide experimental data which will form the basis for useful theories for this region. 52-54

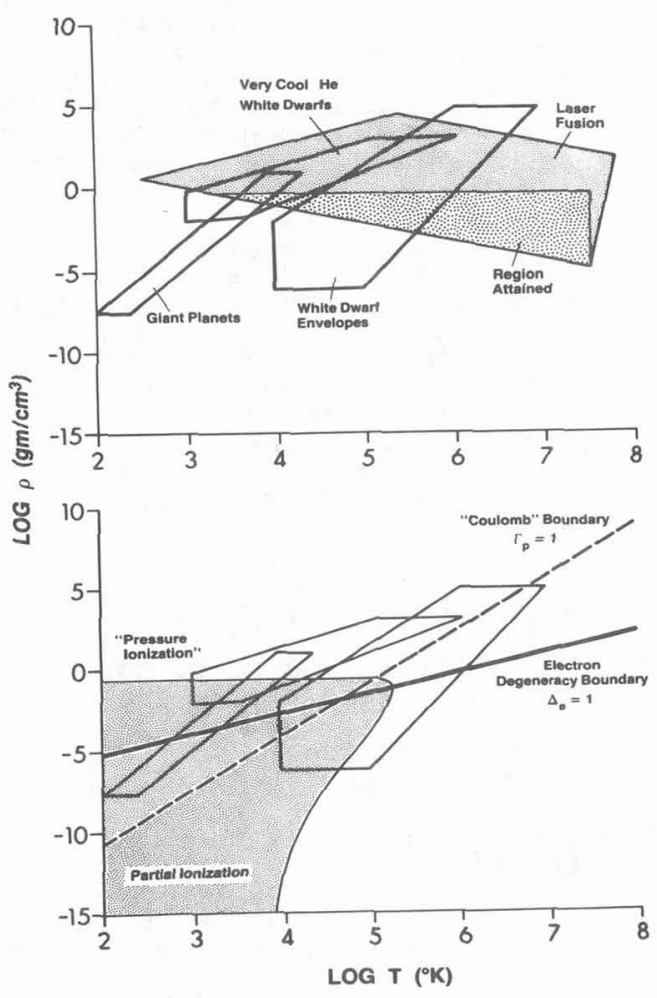

Figure 10 : Density and Temperature Space Showing and 11 the Regions of Parameters Affecting the Equation of state.

Figure 10 taken from Reference 55, shows the regions of density and temperature space which obtain in giant planets, very cool white dwarfs, and the envelopes of white dwarfs. Also shown is the region of interest to laser fusion, including the area which has already been achieved in laser-target experiments. There is considerable overlap between the region achieved in laser target experiments and the regions of astrophysical interest. By using the full power of the OMEGA laser, the boundaries of the regions achievable with lasers will be pushed even further in density and temperature. The equation of state of the plasma is domi- nated by different physics in various areas of $\rho T$ space, as shown in figure 11 taken from reference 56. The exact "boundaries" of these regions need to be determined experimentally.

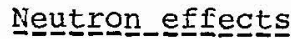

The neutron fluxes currently available by laser-fusion are rather low compared with other devices. However, a neutron yield of around $10^{14}$ neutrons will be possible with the OMEGA laser. Moreover, the neutrons will be monochromatic (14 $\mathrm{HeV})$ and will come from a point source.

A neutron yield of 1014 neutron corresponds to a dose of 400 REM $30 \mathrm{~cm}$ away from the target. Neutron doses of this magnitude with high energy neutrons (10 to $25 \mathrm{MeV}$ ) have been proposed for treatment of cancex 65 . The laser fusion produced neutrons, if used for such purposes, would have the advantage of coming from a point source, so that it would be relatively easy to produce a localized beam.

A major difference between the neutron production by laser-fusion and by other techniques, is the rate of production of neutrons. This is very high in laser fusion devices, with a value of at least $10^{19}$ neutrons/sec on ZETA. Some materials are sensitive to the rate $n^{f}$-rutron irradiation when the rate is above $10^{16}$ neutrons/sec.

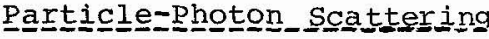

The areas described above have all been related to the high energy density conditions produced by the focused laser on target. The high intensities produced in the absence of a target are more than sufficient ts observe electron-photon standing wave scattering, i.e. Kapitza-Dirac scattering. 57,58

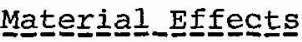

It is well known that high power lasers can damage optical surfaces. Understanding of the mechanism is far from complete, and needs further study. Such study in turn should lead to increased understanding of materials properties. At somewhat lower intensities, annealing of the surface of semiconductors occurs. While this phenomenon does not require a high power laser, different effects dominate at high intensities, and are worth studying. 59 
A more speculative use of high power lasers is use of the laser as a high intensity $x-$ ray source for lithography, for possible application in microcircuit manufacture.

\section{References.-}

1/ M. Lubin, J. Soures, and L. Goldman ; J. Appl. Phys. 44, 1 (January 1973) 347350 .

12/ "Laser Heated Overdense Plasmas for Thermonucleax Fusion", M. Lubin, J. Soures, et. al.; Plenum Press (1972) 43304 67. Presented at the 2nd Workshop at RPI, Laser Interaction and related Plasma Phenomena

/3/ J. Hoose; Appl. Optics 13, 9 (September 1974) 2081 .

/4/ W. Seka, J. Soures, O. Lewis, J. Bunkenburg, D. Brown, S. Jacobs, G. Mourou, and J. Zimmerman; "Design and Performance Characteristics of a High Power Phosphate Glass Laser System", submitted to J. App. Optics (1979).

/5/ "Reproducible Active-Passive Mode-Locked Oscillators", W. Seka and J. Bunkenburg, 14.1, IEEE/OSA CLEA (1977).

16/ "Focusing Systems for High Energy Glass Lasers", S. Kumpan; SPIE Vo1. 103, Systems Integration \& Optical Design II (1977) 41 .

17/ "The OMEGA Fusion Laser System", J.F. Hoose; SPIE, Vol. 103 Systems Integration and Optical Design II (1977)22, and J.M. Eastman,J. A. Boles, J. M. Soures; "Rochester's 30 TW OMEGA System", IASER Focus 14, 12 (1978).

/8/ J. M. Eastman, T. T. Sato and R. Parks; Opt. Eng. 15, 1 (1976) 429.

19/ "An Optical Engineer's Viewpoint of what Large Systems Integration is About", R. E. Hopkins; Optical Workshop OSA Conf., Danbury, Conn. (June 1977).

/10/ "Design of Single Mesh Flashlamp Driving Circuits with Resistive Losses", D. Brown and $N$. Nee; IEEE Transactions on Electron Devices ED-24, 11 (November 1977) 1285

/11/ "The Role of Optical Coating in the Development of High Energy Glass Lasers" S. Refermat; American Vacuum Society, (October 1977).

/12/ W. Seka and J. Bunkenburg; J. Appl. Physics 49, 4 (April 1978) 2277.

/13/ W. Seka, J. Balmer, T. Donaldson, and J. Zimmerman; Optics Comm. 24, (1978) 109.

/14/W. Seka, to be published; (J. Appl. Physics), 1979.

/15/ J. Varon; Rev. Sci. Instr. 48, 7 (JuIy 1977) 941.
/16/ G.M. Halpern, D. C. Leiner D. T. Moore and J. Varon; J. Appl. Physics (1977).

/17/ W. Friedman, G. Halpern, B. Brinker; Rev. Sci. Instr. 45, 10 (October 1974) 1245-1252.

/18/ D. Moore, R. Murray, and F. Neves; Appl. Optics 1724 (December 1978) 39593963.

119/ "Laser Compression Studies at the University of Rochester; M. Lubin, E. Goldman, I. Goldman, J. Delettrez, J. Hoose, S. Jackel, G. Leppelmeier, A. Nee, I. Pelah, E. Thorsos, D. Woodall, and $B$. Yaakobi; IAEA Proceedings of the 6th Conference on Plasma Physics and controlled Nuclear Fusion Reesearch, CN-35/F-2, Berchtesgaden, Germany (October 1976).

120/ "Theory and Interpretation of Laser Compression Studies at the University of Rochester," E. Goldman, J. Delettrez, J. Hoose, S. Jackel, G. Leppelmeier, M. Lubin, A. Nee, I. Pelah, E. Thorsos, D. Woodall, and B. Yaakobi; Conference Proceedings of the Fourth Workshop on "Laser Interaction and $\mathrm{Re}-$ lated Plasma Phenomena" held at RPI, Troy, New York (November 1976), eds. $\mathrm{H}$. Schwarz and H. Hora.

/21/S. Jackel, B. Perry, and M. Lubin; Phys. Rev. Lett. 37, 2 (July 1976) 95.

/22/ J. Delettrez and E. B. Goldman, LLE Report 36, (1976).

/23/ G. A. Moses, Nuc1. Sci. and Engineering 64,1 pp. 49-63 (1977).

/24/ J.P. Boris, Naval Research Laboratory Report 3237 (1976).

/25/ G. B. Zimmerman and W. L. Kruer; Comments on Plasma Physics 2, 51 (1975).

/26/ R. L. McCrory, R. L. Morse, K. A. Taggart; Nuclear Sci. and Eng. 64, Nov. 1977.

/27/ R. S. Craxton and M. G. Haines; Phys. Rev. Lett. 351336 (1975).

/28/ R. S. Craxton and R.L. McCrory, J. Comput. Phys., to be published.

129/ Laboratory for Laser Energetics Annual Report, Vol. 1, pp. 119-122, (1977).

/30/R. I. MCCrory, S. Skupsky, J. Delettrez, and R. S. Craxton, 12 th European Conference on Laser Interaction with Matter, Moscow, USSR (1978).

/31/E. I. Thorsos, T. C. Bristow, J, A. Delettrez, J. M. Soures, and J. E. Rizzo, "Six Beam Irradiation and Implosions of Laser Fusion Targets : Laser Focus Dependence", submitted to J. Appl. Phys. (1979).

/32/ D. Giovanel1i, Los Alamos Scientific Laboratory Report No. IAA-7218-MS, 1978 (unpublished). 
133/ "Implosion, Stability and Burn of MultiShell Fusion Pellets", G. S. Fraley, W. P. Gula, D. B. Henderson, R. L. McCrory, R. C. Malone, R. J. Mason, and R. I. Morse; Plasma Physics and Controlled Nu- $/ 52 /$ C. E. Ragan III, M. G. Silbert, B. C. clear Fusion, 543 (IÄEA, vienna 1975) .

134/ Laser Program Annual Report, 1976, Lawrence Livermore Laboratory Report UCRL50021-76 (1977).

/35/ H. G. Ah1strom, Lawrence Livermore Laboratory, Report No..UCRL-79819, 1977.

/36/ E. K. Storm, et. al., Lawrence Livermore Laboratory Report No. UCRL-79788 (1977).

137/ Lawrence Livermore Laboratory, Laser Fusion Monthly, ed. J. F. Holzrichter, p. 9ff (April 1979).

/38/ K. Estabrook and W. L. Kruer, Phys. Rev. Lett. 4042 (1978).

139/ B. Yaakobi, et. al., Phys. Rev. A., 19, 3, pp. 1247ff (March 1979).

/40/ B. Yaakobi and A. Nee; Phys. Rev. Lett. 36, 18 (May 1976) 1077-81.

/41/ B. Yaakobi, D. Steel, E. Thorsos, A. Hauer, and $B$. Perry ; Phys. Rev. Lett. 39, 24 (December 1977) 1526.

/42/ C. M. Lee and A. Hauer, Appl. Phys. Lett. 33,8 (October 1978) pp. 692-694.

/43/ R. J. Tighe and C. F. Hooper, Phys. Rev. A, 151773 (1973); 17, 410 (1978); C. F. Hooper (private communication).

/44/ "Photometric Measurements with a High Speed Streak Camera", W. Friedman; XI International Congress on High Speed Photography (London, 1974).

/45/ "Dynamic Range and Spatial Resolution of Picosecond Streak Camera", W. Friedman, S. Jackel, W. Seka, and J. Zimmerman; Proceedings of the 12th International Congress on High Speed Photography, Toronto (1976) 544 .

146/ "Review of Diagnostics for Laser Pellet Interaction Experiments", D. Woodall, B. Yaakobi, and M. J. Lubin; from : "Laser Induced Fusion and X-Ray Laser Studies", eds. M. Sargent, M. Scully, and C. Cantrell (Addison Wesley, N.Y., 1976), Vol. $3,191-250$.

/47/ D. T. Attwood, IEEE, J. Quantum Electronics, QE-14, 12 (Dec. 1978).

/48/ R.D. Frankel and J.M. Forsyth, Science 204, pp. 622ff (May, 1979).

149/ B. I. Bennett, J. D. Johnson, G. I. Kerley, and G. T. Rood, Los Alamos Report IA-7130 (1978).

/50/ W. F. Huebner, A. L. Merts, N. H. Magee, and M. F. Argo, LA-6760-M (1977).
"Methods for Opacity Calculations," Los Alamos unpublished manuscript, pp. $1-200$ (1.973). Diven; J. App. Phys. 48,2860 (1977).

/53/ L. Veeser and J. Solem; Phys. Rev. Lett. , 40, 1391, (1978).

/54/ R.M. More, "Laser Driven Shockwave Experiments at Extreme High Pressures", Lawrence Livermore Laboratories Report No. UCRL-83372 (Sept. 1979).

/55/ H. M. Van Horn, "The Physics of white Dwarfs," Physics Today, 32, 1, p. 23ff (Jan, 1979).

/56/ G. Fontaine, H. C. Graboske, Jr., and H.M. Van Horn; Astro. Journal Supp. 35 293-358, Nov. 1977.

/57/ P.I. Kapitza and P. A. M. Dirac, Proc. Cambridge Phil. Soc., 29, 297 (1933).

/58/ J. K. McIver, Jr.; "Consideration of Nonrelativistic Kapitza-Dirac Scattering, "University of Rochester, Ph.D. Thesis (Department of Mechanical and Aerospace Sciences) 1978.

/59/ D. H. Auston, J. A. Golovchenko, A. L. Simons, and $C$. M. Surko, Appl. Phys. Lett. 34 (11), pp. 777ff (June 1979).

160/ S. A. Letzring, "Design and Development of an X-Ray streak Camera for laser Produced Plasma Measurements", University of Rochester, Ph.D. Thesis (Department of Mechanical and Aerospace Sciences) 1979.

/61/ S. A. Letzring and W. Friedman, to be published.

/62/ B. Yaakobi, R. I. McCrory, S. Skupsky, H. Deckman, C. F. Hooper, Jr., P. Bourke, T. C. Bristow, W. Seka, J. Delettrez, and J. Soures, "Direct Measurement of High Density Achieved in Symmetric Compression of Radiationally Cooled Targets", to be published (1979).

163/ S. Skupsky, R. L. McCrory, S. Craxton, and B. Yaakobi, "Short-Pulse, High Power, Target Designs to Āchieve Ignition Threshold conditions", to be published (1979).

/64/ W. Seka, E. Thorsos, R. McCrory, B. Brinker, T. Bristow, J. Delettrez, A. Entenberg, W. Friedman, S. Letzring, J. Rizzo, J. Soures, and B. Yaakobi, "Plastic Coated Glass Microballoon Implosion Experiments", to be published (1979).

/65/ "Particle Radiation Therapy" Proceedings of International Workshop held October 1-3, 1975, sponsored by the American College of Radiology.

/51/W. Huebner, A. Merts and W. Barfield, 